
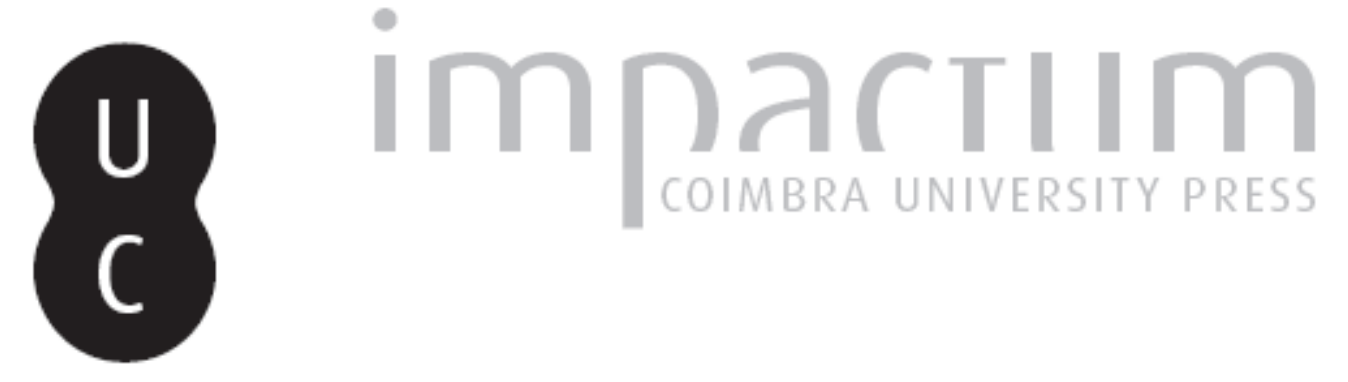

\title{
Peregrino de outras águas: a sombra de Arquíloco em José Jorge Letria
}

Autor(es): Jesus, Carlos A. Martins de
Publicado por: Associação Portuguesa de Estudos Clássicos; Instituto de Estudos Clássicos

URL persistente:

URI:http://hdl.handle.net/10316.2/30479

DOI:

DOI:http://dx.doi.org/10.14195/0872-2110_49_16

Accessed : $\quad$ 26-Apr-2023 10:30:56

A navegação consulta e descarregamento dos títulos inseridos nas Bibliotecas Digitais UC Digitalis, UC Pombalina e UC Impactum, pressupõem a aceitação plena e sem reservas dos Termos e Condições de Uso destas Bibliotecas Digitais, disponíveis em https://digitalis.uc.pt/pt-pt/termos.

Conforme exposto nos referidos Termos e Condições de Uso, o descarregamento de títulos de acesso restrito requer uma licença válida de autorização devendo o utilizador aceder ao(s) documento(s) a partir de um endereço de IP da instituição detentora da supramencionada licença.

Ao utilizador é apenas permitido o descarregamento para uso pessoal, pelo que o emprego do(s) título(s) descarregado(s) para outro fim, designadamente comercial, carece de autorização do respetivo autor ou editor da obra.

Na medida em que todas as obras da UC Digitalis se encontram protegidas pelo Código do Direito de Autor e Direitos Conexos e demais legislação aplicável, toda a cópia, parcial ou total, deste documento, nos casos em que é legalmente admitida, deverá conter ou fazer-se acompanhar por este aviso.

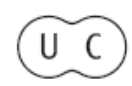




\section{Boletim de}

\section{Estudos Clássicos}

Associação Portuguesa de Estudos Clássicos Instituto de Estudos Clássicos

Coimbra

Junho de 2008 


\section{PEREGRINo de OUTRAS ÁGUAS A SOMbra de ARQuíloco EM JOSÉ JORGE LETRIA}

Raia a aurora que róseos tem os dedos. O poeta, sentado sobre as escarpas de um paredão, durante a noite assaltado pela violência das ondas do Egeu, sente-se embebido nos tempos de outrora que permeiam essas brisas frescas da manhã. Vozes de outros poetas e de outros artistas, os primórdios da palavra, assaltam o poeta que aí se senta em repouso. "Muito respeitinho, que aqui morou um poeta, / na mais perigosa curva das palavras / que matam, libertam e resgatam." (O Fantasma da Obra II, pág. 426) ${ }^{1}$.

Em 1989 José Jorge Letria fazia sair, nos prelos da editora Livros Horizonte, Carta de Afectos, livro de poemas galardoado com o Prémio José Galeno de Poesia da Sociedade Portuguesa de Autores, em 1987. Na página doze deste volume fomos encontrar, agradável surpresa, o poema intitulado "Arquíloco", revelador de um conhecimento notável dos versos e das lendas pseudo-biográficas desse poeta grego do século VII a.C. É esse texto que transcrevemos de seguida e sobre o qual reflectimos, buscando a sua articulação com a poética de Letria, tão centrada na imagética do mar.

Ó Paros, ilha nua sobre as ondas do Egeu

tu que viste nascer Arquíloco

e alimentaste com figos secos

os soldados, os poetas e os navegadores

e embebeste em leite de cabra

as feridas do corpo das mulheres

e te elevaste esguia sobre o mármore

dos cultos e da impaciência dos deuses

revela-me agora se puderes

numa campânula de goivo ou numa abóbada de vento

o segredo primordial do verso capaz

${ }^{1}$ Para a obra poética de J. J. Letria, seguimos as duas antologias com o título $O$ Fantasma da Obra (I e II), editadas respectivamente em 1993 e 2003. Poemas posteriores ou não incluídos nas antologias vêm identificados especificamente. 
de iluminar altivo a fronte dos homens e a nudez astral das estátuas e de cinzelar a coroa das divindades do mar e de se adornar com o mirto e com o sangue perfumado das rosas e da boca dos amantes

O dardo que fere a tua coxa e rasga o braço que em asa se prolonga pode ser de luz ou pode ser de espuma, pode ser de sombra ou mesmo de oiro fino. Mais fundo vai o sulco da idade na pele beijada pelo sol, tão fundo que até a tempestade se demora nos ramos das figueiras para que a morte não desperte quem a espera

Ó Arquíloco, bebe comigo nas alamedas do verão o teu vinho de Ismaras e diz-me que o caos revisitado pode bem ser poesia e que o poeta é aquele que não se poupa e abraçando a chuva ou o fogo conta de si o que idade alguma pode diluir ou apagar.

Declarava José Jorge Letria, em Setembro de 2007, em entrevista à Ensino Magazine: "Nasci perto do mar, em Cascais, e continuo a ter sempre presente na minha memória afectiva o seu cheiro, as suas cores, a sua voz e a sua força. É vizinhança de que um poeta nunca se cura. Foi com o mar que aprendi a imaginar a distância, a viagem e a dimensão do mundo. Ele tem sido meu confidente e meu amigo. Acho que são vozes que se cruzam e completam, que se multiplicam e se iluminam mutuamente. Enfim, coisas da poesia."

O mesmo poeta que, em 1998, publicou a colectânea infantil Lendas do Mar, com ilustrações do filho André Letria, e que em 2001 fez sair na Teorema Os Mares Interiores - livro traduzido no mesmo ano para Espanhol (Ed. Lumen) -, revela um pouco por toda a sua obra essa afectação ao mar. Espaço de memórias, de sonhos e do fantástico, no mar se ouve a "voz do búzio sufocado pelas ondas" (II, pág. 25); é esse o espaço mais directamente conotado com a infância, a "baía das primeiras viagens" (II, pág. 57), ao fundo do qual viaja, como Orfeu em busca de Eurídice vogava aos Infernos, na demanda da palavra primordial, para trazer nos lábios "um feixe de algas, / um coral de tons ferinos, / um rio desaguado em dédalo." (II, pág. 42). Não 
raro, a contemplação do oceano, espelho de infinito, é apenas o ponto de partida para o poema. A essa praia de vida e de sonhos diz pertencer, "à sonolência deste azul, / à nudez das estátuas de areia / povoando a solidão nocturna das praias." (II, pág. 27). Cosmos poético de partida e de regresso, o mar é esse ressoar de vozes antigas, a presença de marinheiros e caravelas dos tempos do mito que partiram, para depois regressar ou não.

Essa "vizinhança de que um poeta nunca se cura" está na base do poema "Arquíloco" que acima transcrevemos, onde conseguimos também ouvir as "vozes que se cruzam e completam, que se multiplicam e se iluminam mutuamente" 2 . Em primeiro lugar, evoca-se a ilha que viu nascer o poeta, Paros, que um epigrama da Antologia Palatina (7. 351) diz ser "a mais escarpada das ilhas sagradas". A alusão a esse local como a "ilha nua sobre as ondas do Egeu" (v. 1) e a referência aos "figos secos" (v. 3) parece remeter para o fragmento 116 West de Arquíloco, de uma linha apenas, onde o sujeito lamenta ter que

deixar Paros, os seus figos e a vida no mar. ${ }^{3}$

Foi Paros quem viu nascer o poeta que, mais do que qualquer outro, fez sua a vida no mar, o poeta que a tradição apresentaria também como soldado. A essa ilha volta Letria, numa viagem sobre as asas do devaneio poético, na busca assumida do "segredo primordial do verso capaz" (v. 11) que há-de ser revelado entre cores e aromas, numa sinestésica "campânula de goivo ou numa abóbada de vento" (v. 10). Em perfeita harmonia com a paisagem poética que ao longo dos séculos caracterizou o mundo grego, pela alusão à brancura do mármore (v. 7) e à "nudez astral das estátuas" (v. 13), a ilha, ponto de observação do infinito espácio-temporal - onde convergem, na

2 Confessou-nos o poeta ter primeiro contactado com os fragmentos de Arquíloco na tradução da Professora M. H. da Rocha Pereira (Hélade ${ }^{1} 1959,{ }^{9} 2005$ ), sendo que depois sentiu necessidade de completar a leitura numa edição francesa de poesia grega. De facto, a antologia que ainda agora referimos contempla apenas, em tradução, 15 fragmentos do poeta de Paros, de um corpus actualmente fixado por M. L. West ${ }^{2}$ em 333 (dos quais, é certo, muitos são demasiado breves para permitir sequer o seu entendimento).

3 Todas as traduções de Arquíloco são nossas, colhidas da tradução dos fragmentos do poeta recém publicada pela Imprensa Nacional - Casa da Moeda (Lisboa, 2008). 
espuma que visita o areal, vozes de todos os tempos - assume-se como sinédoque de uma civilização e de uma forma de cantar a vida. Um canto inaugural, anterior aos próprios poetas, seiva feita de palavras que se não esgotam, é esse "o segredo primordial do verso capaz / de iluminar altivo a fronte dos homens / e a nudez astral das estátuas e de cinzelar / a coroa das divindades do mar" (vv. 11-14).

Símbolos de poesia e da imortalidade que esta granjeia são o mirto e as rosas (vv. 15-16), presentes ambos no fragmento 30 West de Arquíloco:

De ramo de mirto na mão se deleitava, ou com a bela flor da rosa

O mirto e a rosa coroam também as frontes dos amantes, porque glorioso e imortal se quer o amor. Não que esse lirismo estivesse nas intenções de Arquíloco, mais empenhado em cantar um amor libidinoso e animalesco, meio de desonra poética, no contexto de uma poesia iâmbica com fortes intenções invectivas. Mas os poetas são o que escrevem - ou o que deles se conserva, na vertigem dos tempos. Não importa o desenlace de textos como o que transcrevemos, possivelmente uma longa narrativa erótica (ou mesmo obscena), o que dele restou foi um breve e expressivo quadro, eivado de lirismo, onde uma mulher se enfeita e perfuma de flores.

Poeta e soldado, vate das lides da guerra e da paixão, tudo isso foi Arquíloco. Os versos 17-23 do poema de Letria retomam a tradição pseudo-biográfica que o situa na era das colonizações; teria participado activamente nas lutas pela preservação de Tasos - tal como já fizera seu pai, Telésicles - e como tal é natural que tenha enfrentado as violentas tribos da Trácia e de Naxos, que ao tempo se insurgiam contra o domínio daquela ilha por Paros. Letria imagina um soldado ferido, pelo dardo, na coxa e no "braço / que em asa se prolonga" (vv. 17-18); um soldado que ganha, com isso, características de Ícaro, o que ousou voar para além do sonho e quase tocar o sol.

A invocação final a Arquíloco traz consigo outra alusão directa a um fragmento conservado ( 2 West):

Na lança se amassa o pão, na lança o vinho de Ísmaro: bebo na lança recostado. 
Recostados, ambos, numa mesma lança (ou barco) ${ }^{4}$, os dois poetas devem, na cumplicidade imaginada que quebra as barreiras do tempo e do espaço, partilhar segredos sobre o ofício que lhes é comum, a palavra. O "vinho de Ísmaras" é, para Letria, bálsamo de imortalidade, semelhante em tudo ao néctar que só aos deuses que habitam o Olimpo é dado saborear.

Coroas, grinaldas, mirto, rosas, a espuma do mar que Homero dizia marulhante e o vinho, eis os elementos que remetem o poema para um tempo e um espaço que não existem, único local talvez onde se pode buscar esse "segredo primordial" (v. 11). Que segredo? O da Palavra. Arquíloco, hiperbolizado na qualidade de poeta lírico e apaixonado que os textos e testemunhos parecem confirmar não ter sido, é assim o companheiro que, à sombra de uma mesma árvore ou na areia de uma mesma praia, partilha os segredos da sua arte, ele a quem reconhecemos, não obstante, um lugar primeiro na personalização temática da poesia grega.

A outras águas ruma o poeta. Vai provar o sal dessas ondas que desaguam, na fértil brancura da sua espuma, na praia da ilha. Ele é o peregrino que nessas águas busca a voz antiga de outro poeta, outro poeta soldado, como ele, com quem partilhe segredos de um mesmo ofício. Aí morou, e mora ainda, de facto, um poeta.

CARLOS A. MARTINS DE JESUS

4 Este fragmento é dos mais discutidos do poeta, dadas as diferentes interpretações possíveis para o termo dori: lança (opção que seguimos) ou madeiro e, por conseguinte, barco. Ambas são possíveis e foram já defendidas com argumentos válidos. 